DOI 10.5216/ia.v45i3.64893

\title{
ELABORAÇÃO DE MATERIAIS DIDÁTICOS ADAPTADOS AO ENSINO DE QUÍMICA PARA ALUNOS CEGOS
}

\author{
KarLa Suzi Furutani Toyama \\ Universidade Tecnológica Federal do Paraná (UTFPR), Londrina, Paraná, Brasil \\ JACQUELINE LIDIANE DE SOUZA PRAIS \\ Universidade Estadual de Londrina (UEL), Londrina, Paraná, Brasil \\ Marcia Camilo Figueiredo \\ Universidade Tecnológica Federal do Paraná (UTFPR), Londrina, Paraná, Brasil
}

REsUmo: Este artigo teve como objetivo analisar materiais didáticos adaptados ao ensino de Química para alunos cegos, elaborados por licenciandos, a fim de identificar saberes formativos docentes relacionados à proposta do Desenho Universal para a Aprendizagem. A metodologia foi qualitativa, descritiva e classificada como estudo de campo. Para a coleta de dados, ofertou-se um projeto de curso de extensão, no qual participaram 13 licenciandos em Química de uma Universidade Tecnológica Federal do Paraná. A estruturação dos dados foi de acordo com a Análise Textual Discursiva. Os resultados indicam que os participantes, ao criarem materiais didáticos adaptados a partir da perspectiva inclusiva, compreenderam e exploraram outras vias de percepção que favorecem os processos de ensino e de aprendizagem em Química.

Palavras-chave: Educação inclusiva. Desenho Universal para a Aprendizagem. Aluno cego. Formação docente.

\section{INTRODUÇÃO}

A inclusão educacional decorre de vários movimentos de lutas pelo direito de todos à educação, dentre eles destacamos: a Declaração de Salamanca (UNESCO, 1994), a Lei de Diretrizes e Bases da Educação Nacional (BRASIL, 1996), a Política Nacional de Educação Especial na perspectiva da Educação Inclusiva (BRASIL, 2008) e a Lei Brasileira de Inclusão (BRASIL, 2015).

A inclusão educacional pressupõe mudanças na estrutura arquitetônica da escola (facilitando a locomoção dos alunos), recursos humanos (formação de professores, gestão e equipe pedagógica preparada, e envolvimento da família), recursos didáticos e práticas pedagógicas (destacamos os materiais adaptados), proporcionando, assim, o acesso e permanência desses alunos em uma sala de aula.

O objetivo da inclusão é mudar radicalmente o que está cristalizado, padronizado e imposto pela sociedade no geral. Para isso, a perspectiva da inclusão educacional pressupõe uma reforma para a "organização do currículo, da avaliação, da pedagogia, das formas de agrupamento, das escolas e do sistema educacional como um 
todo" (DINIZ, 2012, p. 36). Dessa forma, as escolas precisam acomodar todas as crianças em uma sala regular, sendo elas com necessidades educacionais especiais ou não, assegurando a organização do trabalho pedagógico e reconhecendo suas limitações, suas potencialidades.

Nunes e Lomônaco (2010) explicam que o cego percebe o mundo mediante outros sentidos que não a visão, por exemplo, o tato, ao tocar um objeto; o paladar, que contribui na gustação dos alimentos; o olfato, que auxilia no reconhecimento de pessoas/lugares e a audição.

Nesse contexto, corroborando as ideias de Baptistone et al. (2017), a educação passa a ser inclusiva quando a escola reconhece a diferença apresentada pelos alunos com deficiência e valoriza a diversidade inerente a cada aluno.

Partindo desse pressuposto, verifica-se a necessidade de estudos sobre o referido tema na formação inicial e continuada de professores, uma vez que receberão estes alunos, e, portanto, precisam obter saberes para reconhecer as dificuldades e potencialidades de cada sujeito, elaborar práticas pedagógicas efetivas e satisfazer suas necessidades de aprendizagem.

Conforme Cerqueira e Ferreira (2000), o recurso didático se apresenta como um material físico que visa a auxiliar o educando no processo de ensino e de aprendizagem com mais eficiência. Portanto, sublinhamos a importância de sua utilização de modo adaptado no ensino de Química, uma vez que essa disciplina, ao abranger diversos conceitos e práticas visuais, acaba por excluir os alunos com deficiência visual.

Somado a isso, Baptistone et al. (2017) alertam para a carência de materiais didáticos voltados para o ensino de Química às pessoas com deficiência visual, incluindo as de baixa visão.

O professor precisa organizar suas atividades considerando outras possibilidades de aprendizagem "por meio de descrição, informação tátil, auditiva, olfativa e qualquer outra referência [...]. Por exemplo: a apresentação de vídeo requer descrição oral, os esquemas gráficos devem ser representados em relevo de diferentes texturas" (SÁ et al., 2007, p. 25-27).

No que diz respeito ao ensino de Ciências, destacamos a preocupação dada nas escolas em estimular os alunos a "memorizarem fatos, símbolos, nomes, fórmulas, fazendo com que os alunos não relacionem o conteúdo com seu cotidiano" (PAZ et al., 2008 , p. 2). De tal modo, o professor precisa organizar sua atividade de ensino considerando outras possibilidades de aprendizagem como a "descrição, informação tátil, auditiva, olfativa e qualquer outra referência que favoreçam a configuração do cenário ou do ambiente" (MEYER; ROSE; GORDON, 2002, p. 23).

Nesse contexto, os princípios do Desenho Universal para a Aprendizagem (DUA ou Universal Designer Learning, UDL) oferecem subsídios didáticos para essa organização do ensino de modo inclusivo. Conforme Meyer, Rose e Gordon (2002), o DUA consiste em uma proposta de organização curricular que orienta o planejamento de ensino e a prática pedagógica de modo inclusivo. De acordo com Prais (2016), a abordagem do DUA considera a aplicação de três princípios ao planejamento e à prática pedagógica: 
TOYAMA, K. S. F.; PRAIS, J. L. de S.; FIGUEIREDO, M. C.

\begin{abstract}
(i) possibilitar múltiplas formas de apresentação do conteúdo, (ii) promover diversas formas de ação e expressão do conteúdo pelo aluno, (iii) proporcionar vários modos de aprendizagem e desenvolvimento organizados pelo professor para os alunos promovendo a participação, interesse e engajamento na realização das atividades pedagógica. (PRAIS, 2016, p. 45).
\end{abstract}

Segundo Prais (2017, p. 71), a abordagem do DUA "assume objetivos e estratégias para uma proposta didática de ensino, que visa a satisfazer as necessidades de aprendizagem de um maior número de alunos em sala de aula". Somado a isso, a autora sublinha que o recurso didático é um meio para consecução dos objetivos do professor, possibilitando e potencializando a aprendizagem de todos os alunos. De tal modo, diversificar estratégias de ensino e saber prover recursos didáticos é um dos saberes a ser contemplado na formação docente (MANTOAN, 2015), principalmente se tratando da inclusão educacional de alunos com deficiência na classe comum.

Além disso, destacamos as orientações presentes na Cartilha da Inclusão Escolar: inclusão baseada em evidências científicas, de 2014, que apresenta um conjunto de recomendações gerais para professores de Química, Física e Ciências para inclusão de alunos cegos, garantindo o acesso, permanência e o aprendizado (COMUNIDADE APRENDER CRIANÇA, 2014). Dentre elas, sublinhamos que as orientações didáticas para a exploração de esquemas/gráficos e manuseio de materiais devem ser feitas junto do aluno e, se possível, antecipadamente, bem como a utilização de gráficos, mapas, tabelas etc., em Braille ou apenas em relevo.

De tal modo, este artigo teve como objetivo analisar materiais didáticos adaptados ao ensino de Química para alunos cegos, elaborados por licenciandos, a fim de identificar saberes formativos docentes relacionados à proposta do Desenho Universal para a Aprendizagem. É importante salientar que, a escolha da abordagem curricular do DUA foi priorizada porque contempla princípios que favorecem a produção de materiais didáticos inclusivos e atende às necessidades de aprendizagem dos alunos.

\title{
PROCEDIMENTOS METODOLÓGICOS
}

Neste trabalho, em termos de metodologia, a pesquisa foi qualitativa, descritiva e caracterizada como de campo, pois proporciona aos pesquisadores o contato direto e prolongado com o ambiente e a situação que está sendo investigada; portanto, o investigador coleta os dados no campo para depois analisá-los. (LÜDKE; ANDRÉ, 1986; BODGAN; BIKLEN, 2003).

A pesquisa ocorreu no âmbito de um projeto de curso de extensão, que também estava vinculado ao Trabalho de Conclusão de Curso de uma das autoras (TOYAMA, 2019). A coleta de dados ocorreu em um sábado do mês de maio de 2019 e teve a duração de 6 horas e 30 minutos. O local foi as dependências de uma Universidade Tecnológica Federal do Paraná. Para participação no projeto de curso de extensão foi disponibilizado um formulário no Google Forms ${ }^{\circledR}$, e 13 (treze) acadêmicos do curso de Licenciatura em Química efetivaram sua inscrição.

Em relação aos instrumentos de coleta de dados, utilizamos a aplicação de questionários inicial e final, notas de campos, somados à gravação em áudio do 
encontro formativo e registro de fotos dos materiais que foram confeccionados pelos participantes.

Durante a realização do projeto, os licenciandos tiveram a oportunidade de conhecer e discutir sobre os pressupostos da Educação Inclusiva e os princípios do Desenho Universal para a Aprendizagem (DUA), além de conhecerem alguns materiais didáticos adaptados para o ensino de Química. Ao fim, a atividade proposta culminou na elaboração de materiais didáticos adaptados a partir de conceitos químicos definidos pelos participantes e planificados em recursos acessíveis à aprendizagem de alunos cegos. Para isso, oferecemos aos licenciandos recursos como: cola, tesoura sem ponta, folhas de diversas texturas de EVA, botões, papéis, barbante, bolinhas de isopor, dentre outros materiais de baixo custo.

De posse dos recursos de baixo custo para a confecção dos materiais adaptados ao aluno cego, os participantes se organizaram espontaneamente em 6 grupos, contendo de 2 a 3 licenciandos em cada um, para discutirem sobre o assunto a ser trabalhado no ensino de Química e os recursos a serem utilizados.

Baseados nos conhecimentos adquiridos no projeto de curso de extensão, os grupos puderam definir com autonomia as áreas e os conteúdos que foram planificados nos materiais, conforme o quadro 1.

Quadro 1 - Elaboração de materiais didáticos adaptados no ensino de Química para alunos cegos

\begin{tabular}{|c|c|c|}
\hline Grupo & Área do conhecimento & Conteúdo \\
\hline A & Físico-Química & Solubilidade \\
\hline B & Química Orgânica & A química da gasolina \\
\hline C & Bioquímica & Proteína \\
\hline D & Química Geral & Átomo de Rubídio \\
\hline E & Química Geral & Estados físicos da água \\
\hline F & Química Geral & Camada de Valência e Diagrama de Linus Pauling \\
\hline
\end{tabular}

Fonte: Dados da pesquisa

Após as confecções dos materiais didáticos adaptados, os participantes apresentaram suas propostas descrevendo os recursos utilizados, os conteúdos abordados e as dificuldades para ensinar o conceito químico para um aluno cego.

O método de interpretação e organização dos dados foi realizado a partir da Análise Textual Discursiva (ATD), que permitiu a análise, organização e interpretação dos materiais de pesquisa logo após a coleta de dados (MORAES; GALIAZZI, 2006). Dessa forma, o método permitiu ler e interpretar os dados e as respostas dos licenciandos visando à qualificação dos resultados.

A partir das análises, foram encontradas duas categorias emergentes: i) Conhecimentos prévios dos estudantes, ii) Materiais didáticos adaptados para o ensino de Química, que são apresentadas na próxima seção.

\section{RESULTADOS E DISCUSSÃO}


TOYAMA, K. S. F.; PRAIS, J. L. de S.; FIGUEIREDO, M. C.

\section{CONHECIMENTOS PRÉVIOS DOS ESTUDANTES}

Com base nos resultados obtidos no questionário inicial, identificamos que os 13 participantes tinham entre 18 e 49 anos, sendo que estavam presentes alunos desde o $1^{\circ}$ até o $8^{\circ}$ período do curso, ou seja, houve representantes de todos os períodos da licenciatura em Química.

Verificamos que nenhum dos 13 alunos tinha conhecimento em relação à definição do conceito de Educação Inclusiva, sendo que 5 deles confundiram com a Educação Especial. Esses resultados evidenciam que, apesar de anos de luta em favor da educação para todos, a Educação Inclusiva ainda acaba sendo confundida com a Educação Especial, que, atualmente, além de ser uma modalidade de ensino (BRASIL, 1996), se constitui em uma gama de conhecimentos que favorecem a inclusão de seu público-alvo no contexto regular.

Desse modo, isso é previsto, pois estes alunos estiveram historicamente excluídos do processo de escolarização e são reconhecidos como desafios para as escolas regulares atenderem suas particularidades no processo de aprendizagem (MANTOAN, 2015). Todavia, após o projeto de curso, a maioria $(77 \%$ - 10) dos participantes obteve um progresso em suas explicações.

Quanto ao conhecimento de material didático adaptado para a inclusão do aluno cego no ensino de Química, 69\% dos participantes, isto é, 9 deles, disseram ter algum conhecimento, sendo o Braille e áudio descrição os recursos comentados. Segundo Sampaio e Mol (2017), tais ferramentas facilitam o processo de ensinoaprendizagem uma vez que o professor deve falar ou descrever detalhadamente cada ação tomada.

\section{MATERIAIS DIDÁTICOS ADAPTADOS PARA O ENSINO DE QUÍMICA}

Para a confecção dos materiais, além de serem simples e baratos, cada organizador do referido projeto trouxe de suas casas aquilo que tinham (como pedaço de pano, barbante, botões, cola, dentre outros). Assim, para a construção dos materiais, coube aos participantes atentarem-se aos conhecimentos adquiridos no curso, domínio do conceito químico e escolha adequada quanto aos recursos para a representação de um conteúdo curricular da área do conhecimento de Química.

Dessa forma, foi possível notar que a metade dos materiais didáticos adaptados (03) e confeccionados contemplou os conteúdos de Química Geral. Os demais grupos abordaram assuntos nas áreas da Química Orgânica (um trabalho), Físico-Química (um trabalho) e Bioquímica (um trabalho).

O grupo A abordou o conceito de solubilidade, explicando os tipos de soluções insaturada, saturada e supersaturada (Figura 1). 


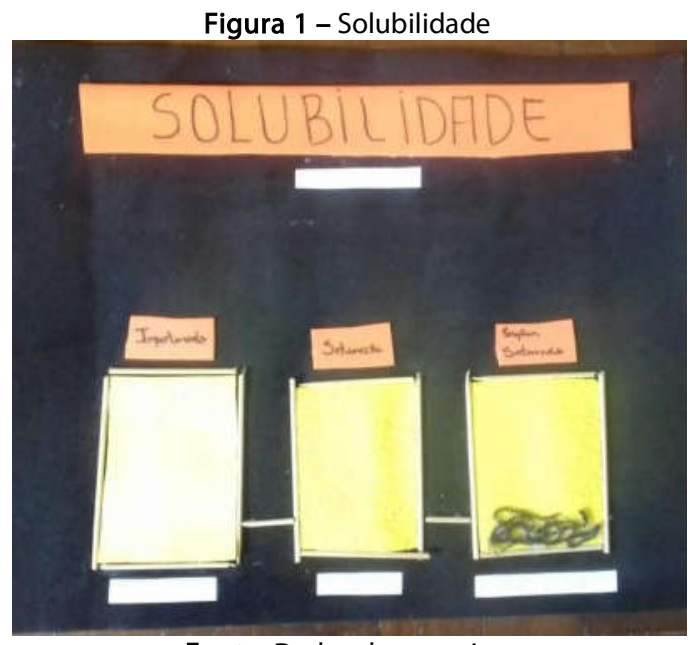

Fonte: Dados da pesquisa.

De acordo com os 2 integrantes do Grupo A, em seu material (Figura 1), o aluno cego poderá utilizar de percepções como o tato (ao sentir as diferentes texturas entre as soluções insaturada, das saturadas e supersaturadas). O grupo salientou que a temática poderá ser abordada tanto visivelmente (processo mais comumente utilizado em sala de aula) quanto de maneira tátil (como o trabalho confeccionado, por exemplo), bem como fazendo uso do paladar (ao sentir o gosto do suco em pó quando se coloca muita ou pouca água).

Quanto à dificuldade encontrada na confecção deles, um dos membros comentou ter encontrado em "escolher o melhor material para ilustrar a supersaturada através da textura. Se colocava metade de uma textura e outra metade com outra textura, mas daí seria heterogêneo". Percebemos a preocupação do aluno em ilustrar da melhor maneira o conceito para que o aluno não tenha dificuldade em relacioná-lo com a teoria. Para a confecção do material, o grupo utilizou: folhas de EVA coloridas, folha de EVA texturizada, tesoura, cola, palitos de churrasco, pedaço de barbante, fio de metal e canetas hidrográficas.

De tal modo, percebemos que o grupo A ressaltou a implementação do Princípio 1 da proposta do DUA ao possibilitar múltiplas formas de apresentação do conteúdo, explorando também materiais com diferentes texturas e tornando acessível ao aluno cego o conceito químico de solubilidade.

O grupo B tratou sobre a Química da gasolina (Figura 2), uma vez que os integrantes lecionaram o assunto em uma escola estadual da qual faz parte o Programa de Residência Pedagógica (um programa da Capes - Coordenação de Aperfeiçoamento de Pessoal de Nível Superior que compõe a Política Nacional de Formação de Professores). Esse grupo utilizou em sua produção: papel Kraft, folhas de diferentes texturas de EVA, tesoura, papel ondulado, cola, barbante e canetas hidrográficas. 
TOYAMA, K. S. F.; PRAIS, J. L. de S.; FIGUEIREDO, M. C.

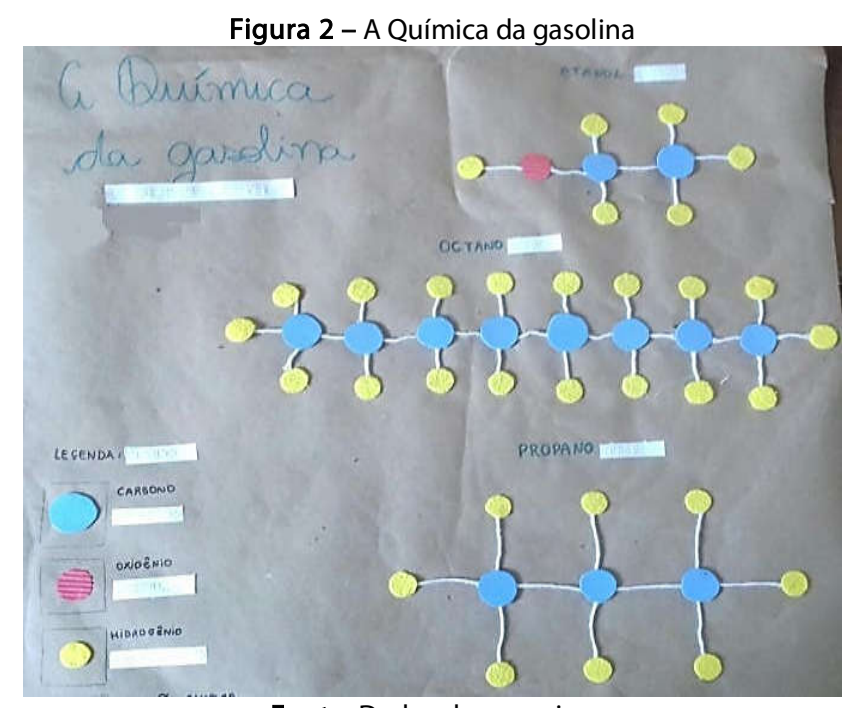

Fonte: Dados da pesquisa.

De acordo com os 2 integrantes do grupo B, com o material didático adaptado, visualizado na Figura 2, o aluno cego poderá conhecer pelo tato as fórmulas estruturais de alguns combustíveis como: o etanol, o octano e o propano. Esclareceram que, ao tatear as estruturas, o aluno irá perceber as diferenças e/ou semelhanças entre cada átomo, relacionando-os à textura e ao tamanho de cada um.

Umas dos integrantes do grupo B salientou o seguinte na criação do material didático adaptado: "O interessante foi que fizemos em colorações distintas. Então não seria um trabalho apenas para o aluno cego; ele seria um trabalho realmente para a Educação Inclusiva pois ele está trabalhando também o visual". Vale lembrar que é importante que o aluno cego saiba que existem diversas cores e que elas estão associadas a diferentes formas e texturas, as quais contribuem para a compreensão do conceito de fórmulas estruturais.

Outro participante do grupo B relatou que "deixamos bem simplório porque acho que quanto mais simples for, você podendo descomplicar, fica melhor para o aprendizado [...]. Simplória do ponto de vista do aprendizado".

Assim, identificamos a preocupação do grupo B na elaboração de um material inclusivo e acessível para todos, pois, durante a apresentação, os participantes ressaltaram a importância da sua utilização no planejamento de ensino, estando, assim, de acordo com o Princípio 1 da proposta do DUA ao ofertar múltiplas formas de apresentação do conteúdo (PRAIS, 2016); bem como relataram a necessidade de, durante a aula, promover diversas formas de ação e expressão do conteúdo pelo aluno, como no Princípio 2 do DUA (PRAIS, 2016). Dessa maneira, ao considerar a participação ativa do aluno durante as aulas, o grupo $B$ contemplou, em sua proposta de utilização desse recurso, o Princípio 3 do DUA, que diz respeito a "proporcionar vários modos de aprendizagem e desenvolvimento, organizados pelo professor para os alunos, promovendo a participação, interesse e engajamento na realização das atividades pedagógicas" (PRAIS, 2016, p. 46). 
Quanto à dificuldade em fazer o material, o grupo B informou não ter tido, afirmou que foi bem fácil pensar; apenas teria caso fosse para a aula experimental, pois teriam que replanejar uma vez que, conforme a aluna explicou: "Para essa aula, poderia trabalhar as estruturas em sala de aula e trabalhar a contextualização".

O grupo C (contando com 2 integrantes) abordou o conceito da Proteína, de acordo com a Figura 3. A dificuldade em imaginar sua estrutura tridimensional durante a aula de Bioquímica levou o grupo a realizar um material adaptado como forma de facilitar a compreensão do conceito para os alunos cegos e videntes, pois de acordo com o aluno: "Se para as pessoas que enxergam já é dificil de entender, pro aluno que tem deficiência visual é mais difícil ainda".

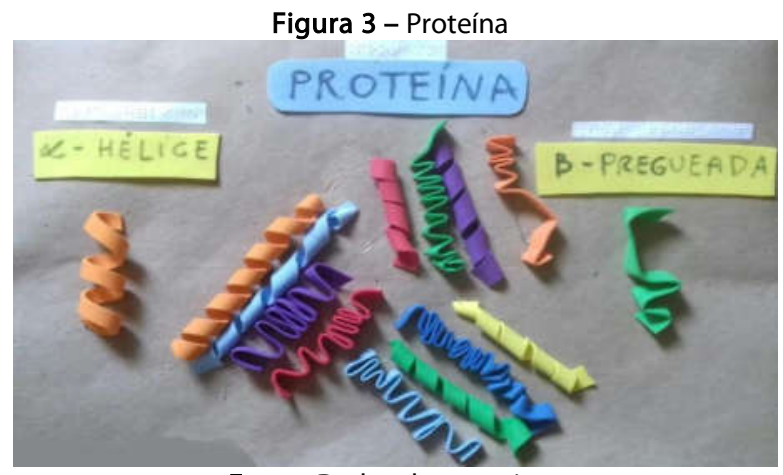

Fonte: Dados da pesquisa.

No material didático da Figura 3, com o tato, o aluno cego (e vidente) conhecerá as diferentes estruturas da proteína (helicoidal e pregueada), uma vez que a estrutura em 3D facilita na compreensão do conteúdo e auxilia na apreensão da teoria. Tal pressuposto é coerente com a proposta do DUA, ao considerar a necessidade de implementar diferentes formas de apresentar o conteúdo (Princípio 1). Os materiais utilizados foram: papel Kraft, folhas de EVA coloridas, tesoura, cola quente e canetas hidrográficas.

A dificuldade encontrada pelo grupo $\mathrm{C}$ foi em deixar no formato correto, uma vez que a "cola fez uma bagunça pois não sabia se estava saindo pouco ou muito". Destacamos que, ao orientar o trabalho para um aluno cego, os materiais devem ser de boa qualidade para facilitar na construção. Somado a isso, ao considerar a implementação do Princípio 2 do DUA (promover diversas formas de ação e expressão do conteúdo pelo aluno), o grupo B explicou em sua apresentação que o material didático adaptado seria construído junto a todos os alunos. Este tipo de possibilidade didática de construção durante a aula é denominado pela proposta do DUA como processo de planificação (MEYER; ROSE; GORDON, 2002).

O grupo D (com 3 integrantes) escolheu representar o Átomo de Rubídio pois, além de já terem trabalhado em uma escola estadual pelo Programa de Residência Pedagógica, o grupo pensou em facilitar a compreensão dos alunos ao estourar os fogos de artifício e aparecerem diversas cores. 
TOYAMA, K. S. F.; PRAIS, J. L. de S.; FIGUEIREDO, M. C.

Um dos integrantes do referido grupo comentou que um dos motivos de optar pela temática foi o de "trazer uma situação do cotidiano, lá do Ano Novo, pro pessoal". Os recursos utilizados foram: papel Kraft, folhas coloridas de EVA, bolinhas de 2 tamanhos diferentes, lantejoulas, cola quente, tesoura, barbante, aro de metal, rolo de papelão, bola de isopor e canetas hidrográficas.

Figura 4 - Átomo de Rubídio

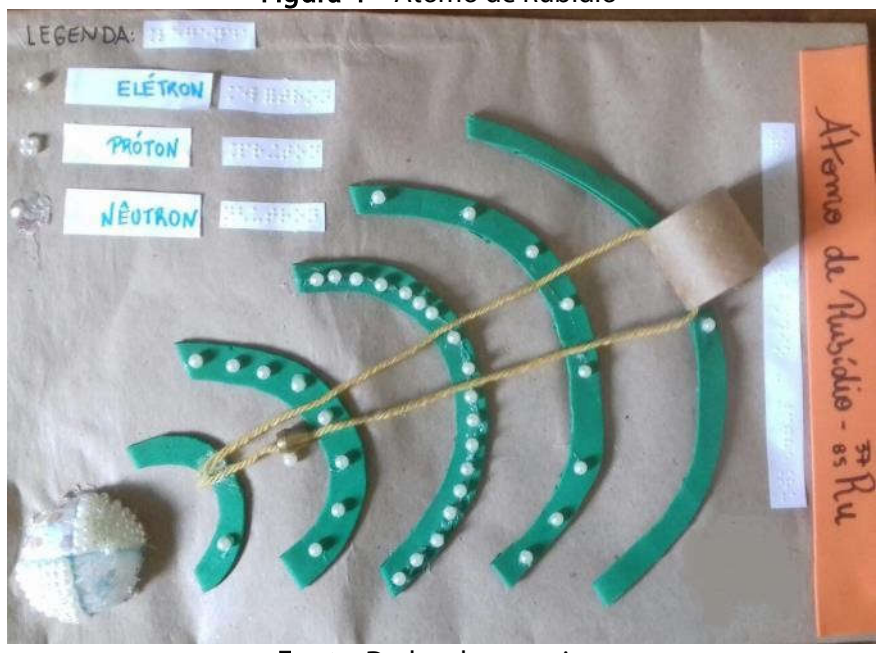

Fonte: Dados da pesquisa.

Podemos verificar, na Figura 4, que o grupo D construiu as camadas eletrônicas para explicar o salto do elétron de um nível de energia ao outro e se preocupou em utilizar diferentes texturas, conforme o aluno relatou: "A pérola maior é o elétron, $O$ nêutron a gente usou as lantejoulas e o próton são as pérolas menores". Assim, por meio do tato, o aluno cego perceberá o conceito com mais propriedade, pois conseguirá construir, mentalmente, o processo.

O relato do aluno e a preocupação do grupo $D$ na elaboração desse material didático adaptado revelam que o conhecimento da proposta do DUA favoreceu a construção de recurso que agrega à prática pedagógica do professor a aplicação dos princípios, além de considerar a vivência prática do conteúdo como ponto de partida. Por sua vez, essa estratégia de ensino é indicada pelo material da Comunidade Aprender Criança (2014) para o ensino de conceitos científicos a alunos cegos de modo inclusivo.

A dificuldade encontrada pelo grupo foi colar as pérolas e lantejoulas, pois, ao utilizar a cola quente, aqueceu um pouco os dedos dos integrantes. Salientamos, mais uma vez, a importância da escolha dos materiais para que não ocorra acidentes ao deixar o aluno cego fazer sua atividade, desenvolvendo, assim, sua autonomia (sob supervisão de uma pessoa vidente).

O grupo E (com 2 integrantes) desenvolveu um material sobre os Estados Físicos da água, de acordo com a Figura 5, em razão do tema estar presente no cotidiano dos alunos. Tal escolha é coerente em relação aos pressupostos inclusivos em buscar aproximar o aluno da vivência prática com os conteúdos estudados (COMUNIDADE APRENDER CRIANÇA, 2014). 
De acordo com o grupo $\mathrm{E}$, as diferentes estruturas da água serão percebidas pelo aluno cego ao tatear, de maneira que, no estado gasoso, as moléculas estão mais separadas e no sólido, mais juntas. As ferramentas utilizadas para esse material adaptado foram: papel Kraft, barbante, folha de EVA, bolinhas, algodão, lantejoulas, tinta, pedrinhas, tesoura, cola, cola quente e canetas hidrográficas.

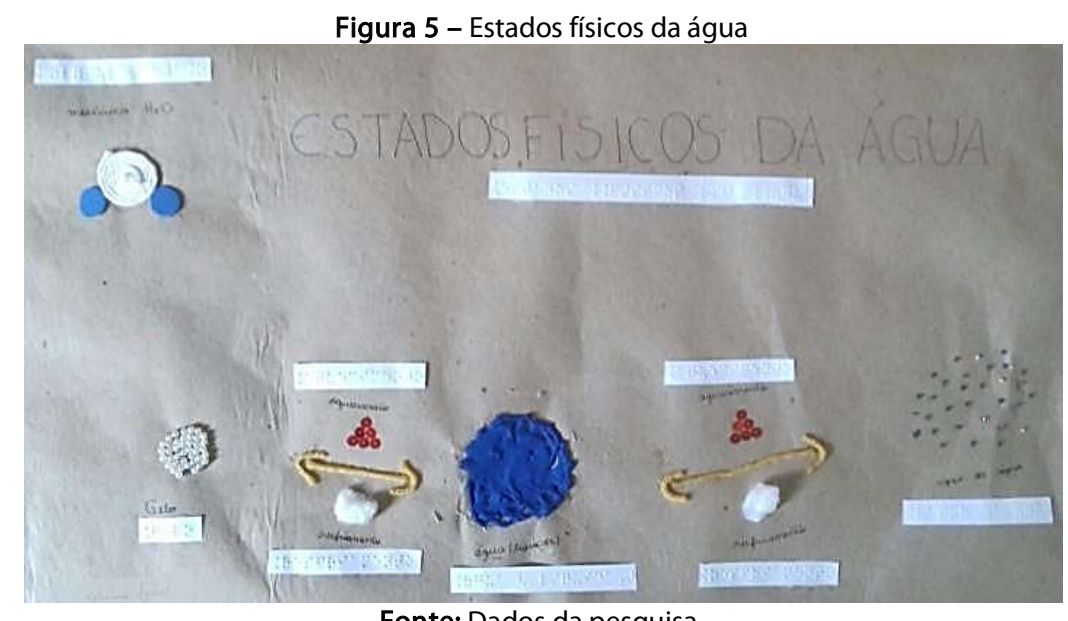

Fonte: Dados da pesquisa.

Com o material didático representado na Figura 5, o aluno cego conhecerá os estados físicos da água e a mudança de uma condição a outra, percebendo as diferenças de texturas entre as 3 condições da água (gelo, água e vapor), além das semelhanças nos processos de transição entre um estado e outro. Assim, percebemos que a proposta do grupo E planifica a aplicação do Princípio 1 do DUA - possibilitar múltiplas formas de apresentação do conteúdo.

Percebemos que o grupo $\mathrm{E}$ se preocupou em não utilizar materiais muito ásperos para não prejudicar o aluno cego ao tatear, conforme um dos integrantes do grupo relatou: "Tem que tomar cuidado se o material é muito áspero pois daí muda a sensibilidade dele para outras coisas, igual foi falado no curso [...] e imagina se machucar o dedo do aluno cego, ele realmente vai ficar 'cego'". Aqui, entendemos que esse grupo teve cuidado na escolha dos materiais, preferindo não utilizar a lixa, pois identificaram que afetaria a sensibilidade dos dedos do aluno cego para reconhecer os objetos, conforme orientações didáticas da área (COMUNIDADE APRENDER CRIANÇA, 2014).

O grupo $\mathrm{F}$ (com 2 integrantes) elaborou um material didático adaptado contemplando o conteúdo de Camada de Valência e o Diagrama de Linus Pauling (Figura 6). 
TOYAMA, K. S. F.; PRAIS, J. L. de S.; FIGUEIREDO, M. C.

Figura 6 - Camada de Valência e Diagrama de Linus Pauling

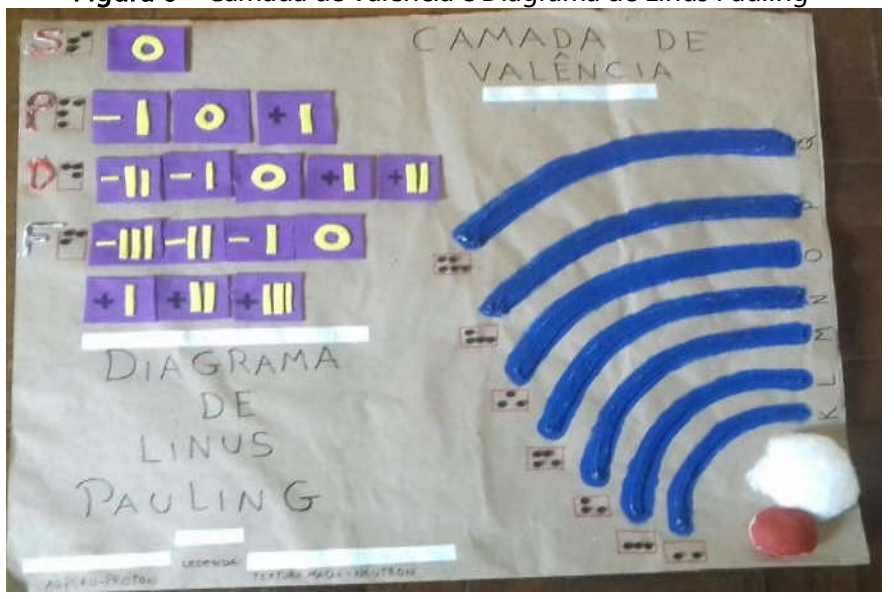

Fonte: Dados da pesquisa.

A escolha do grupo $F$ para o tema se deu por terem acabado de ver o conteúdo na universidade, por ser um conteúdo possível de ser abordado com os alunos do ensino médio, além de ser mais fácil de compreendê-lo na prática.

Identificamos que o grupo $\mathrm{F}$ se preocupou em distinguir os níveis de energia por meio da espessura conforme o seu crescimento (já que a quantidade de barbante utilizada foi aumentando à medida que os níveis de energia se distanciavam do núcleo). A dificuldade encontrada foi fazer as texturas de modo que facilitassem o acesso do aluno cego. Para esse material foram utilizados: Papel Kraft, barbante, folhas coloridas de EVA, tinta, tesoura, bola de isopor, algodão, cola e canetas hidrográficas.

Ao analisar a proposta de material elaborado pelo Grupo F, percebemos que ela está alinhada ao Princípio 1 do DUA, bem como a sugestão para apresentação desse conteúdo utilizando recurso de baixo custo e de modo acessível aos alunos cegos. Com esse material (Figura 6), o aluno cego compreenderá mais facilmente, por meio do tato, as diferentes camadas de valência que envolvem o núcleo, assim como seus subníveis de energia.

Constatamos que todos os grupos conseguiram confeccionar seus trabalhos de acordo com o imaginado e contemplaram o princípio 1 do DUA, que seria pensar além da explicação oral, ou seja, uma outra forma de apresentação do conceito químico. Em geral, a principal dificuldade encontrada foi pensar na elaboração de suas aulas, de maneira inclusiva, fazendo uso de tais ferramentas, já que os participantes relataram não terem contato com pessoa cega e que, portanto, se sentiam inseguros em orientá-la da melhor maneira.

Sampaio e Mol (2017) afirmam a necessidade da inserção de materiais didáticos no ensino de Química, de acordo com a necessidade do aluno, para que ele não se sinta em desvantagem em relação aos alunos videntes.

Para o aluno com Deficiência Visual, os materiais didáticos devem ser adaptados, transcritos para o Braille, em relevo ou de outras formas, as quais permitam que o aluno tenha acesso ao conteúdo (PIRES, 2010). Vale salientar a preocupação dos participantes em confeccionar trabalhos voltados não somente aos alunos cegos, mas 
também aos alunos videntes, uma vez que as escritas em Braille e na Língua Portuguesa se fizeram presentes.

A utilização dos recursos de baixo custo e de texturas variadas proporcionou aos participantes a elaboração de materiais didáticos adaptados quanto ao ensino dos conceitos químicos, sendo que o tato foi o sentido mais acionado.

O tato faz uma leitura sequencial da informação, assim, muitas informações em um pequeno espaço, ou mesmo poucas em um espaço muito grande, dificultam a aquisição e/ou processamento das informações, prejudicando a compreensão desses recursos e demais configurações bidimensionais (COMUNIDADE APRENDER CRIANÇA, 2014. p. 12).

Com o tato, o aluno DV (Deficiente Visual) consegue perceber as características dos objetos (assim como a textura, o formato, a temperatura, as dimensões etc.), garantindo as mesmas concepções que os alunos videntes, necessitando somente de um maior tempo para a sua percepção quando comparada à percepção visual, pois se faz necessário toda uma construção mental do objeto a que se refere. Portanto, o uso de recursos didáticos apropriados é importante para a inserção e permanência de alunos cegos nas aulas (BAPTISTONE et al., 2017).

Assim, a utilização dos materiais adaptados aos alunos cegos elaborados pelos participantes poderá auxiliar o professor no ensino de diversas áreas da Química: FísicoQuímica, Química Orgânica, Bioquímica e Química Geral.

Orientações didáticas são de extrema importância para o bom direcionamento e planejamento de uma aula inclusiva, dentre elas podemos destacar: os próprios alunos podem orientar o aluno cego no desenvolvimento de atividades propostas pelo professor em uma sala de aula (e não somente o professor de apoio); compreender as necessidades e o conhecimento que o aluno cego possui do mundo, ou seja, se ele já foi vidente algum dia e se possui uma memória visual que facilite na hora da elaboração de atividades; em aulas práticas, fazer o reconhecimento dos materiais a serem utilizados para auxiliar na hora do aluno com Deficiência Visual manusear; desenvolver a autonomia do aluno cego, dentre outras.

\section{CONSIDERAÇÕES FINAIS}

Percebemos que a participação dos licenciandos no projeto de curso de extensão contribuiu para aprenderem saberes formativos docentes durante a elaboração de seus materiais didáticos adaptados, pois consideraram pressupostos inclusivos e os princípios do Desenho Universal para a Aprendizagem (DUA). Nesse contexto, observamos que os licenciandos, ao organizarem as adaptações, tomaram para si e vivenciaram as necessidades e limitações de alunos cegos para confeccionarem materiais que favorecessem o acesso à aprendizagem, atendendo às suas limitações e explorando outras formas de ensinar e aprender os conteúdos, a não ser exclusivamente o da visão. 
TOYAMA, K. S. F.; PRAIS, J. L. de S.; FIGUEIREDO, M. C.

Somado a isso, identificamos que os participantes pensaram durante a criação dos materiais didáticos adaptados em como eles seriam utilizados nas aulas, revelando, assim, que os recursos não seriam um mero atrativo ou embelezamento da prática pedagógica, mas um meio para propiciar a apresentação do conteúdo, ação e procedimento da aprendizagem pelos alunos e suas estratégias de engajamento durante a aula, conforme indicado pela proposta do DUA.

Pudemos identificar também que, além de considerarem o processo de planificação dos conceitos químicos, os licenciandos selecionaram materiais que não requerem grandes investimentos financeiros e que, ao utilizarem com seus (futuros) alunos, possibilitarão uma aula mais atrativa, com aprendizagem igualitária, atendendo às necessidades de cada aluno, em especial, dos alunos cegos.

Analisamos que os materiais didáticos elaborados pelos licenciandos favorecem o conhecimento dos docentes em meio às possibilidades de diversificarem e incluírem os alunos cegos em suas aulas, pois permitem aulas que visam a promover o engajamento do aluno com o conteúdo (uma vez que ele consegue assimilar a teoria com o material didático adaptado), promovem ações colaborativas dentro da sala de aula, motivam o aluno a participar das atividades propostas, agregando, dessa forma, sentido à Educação Inclusiva e garantindo, portanto, a equidade escolar, uma vez que os recursos didáticos adaptados irão auxiliar a todos os alunos dentro da sala de aula de maneira igualitária.

Entendemos que a participação dos licenciandos em Química durante o projeto de curso de extensão promoveu tempos e espaços para compreenderem a importância de promover aulas inclusivas, garantir a autonomia de seus alunos (visto que a cegueira não é condição de ser dependente), conhecer o aluno cego antes de preparar suas atividades (para compreender aquilo que ele já sabe) e de realizar diferentes materiais didáticos adaptados.

Dessa forma, sugerimos que os materiais didáticos propostos sejam testados e validados por pessoas e alunos cegos a fim de (re)elaborar, modificar e utilizar na prática pedagógica de professores que ensinam Química na Educação Básica, na qual lhe caberá somente a criatividade e dedicação para confeccionar suas ferramentas de trabalho, contribuindo para uma aprendizagem mais inclusiva.

Artigo recebido em: 08/08/2020 Aprovado para publicação em: 03/11/2020

\section{THE CREATION OF ADAPTED TEACHING MATERIALS IN TEACHING CHEMISTRY TO BLIND STUDENTS}

ABSTRACT: This article aimed to analyze adapted teaching materials to teaching of Chemistry for blind students, developed by undergraduate students, in order to identify teacher training knowledge related to the Universal Designer Learning proposal. The methodology was qualitative, descriptive and classified as a field study. For data collection, an extension course project was offered, which 13 undergraduates in Chemistry from a Federal Technological University of Paraná participated. The data was structured according to the Discursive Textual Analysis. The results 
indicate that the participants when creating adapted teaching materials, from an inclusive perspective and, above all, understood and explored other ways of perception that favor the teaching and learning processes in Chemistry.

KEYWORDS: Inclusive Education. Universal Designer Learning. Blind student. Teacher Training.

\section{ELABORACIÓN DE MATERIALES DIDÁCTICOS ADAPTADOS EN ENSEÑANZA DE QUÍMICA A ESTUDIANTES CIEGOS}

RESUMEN: Este artículo tuvo como objetivo analizar materiales didácticos adaptados a la enseñanza de Química para estudiantes ciegos, desarrollados por estudiantes de pregrado, con el fin de identificar el conocimiento de capacitación docente relacionado con la propuesta de Diseño Universal para el Aprendizaje. La metodología fue cualitativa, descriptiva y se clasificó como un estudio de campo. Para la recopilación de datos, se ofreció un proyecto de curso de extensión, en que participaron 13 estudiantes universitarios de Química de una Universidad Tecnológica Federal de Paraná. Los datos se estructuraron de acuerdo con el análisis textual discursivo. Los resultados indican que los participantes al crear materiales didácticos adaptados, desde una perspectiva inclusiva $y$, sobre todo, entendieron y exploraron otras formas de percepción que favorecen los procesos de enseñanza y aprendizaje en Química.

PALABRAS CLAVE: Educación Inclusiva. Diseño Universal para el Aprendizaje. Estudiante Ciego. Formación Del Profesorado.

\section{REFERÊNCIAS}

BAPTISTONE, G. F; MATTOS NETO, I. A.; TOYAMA, K. S. F.; PRAIS, J. L. S. A inclusão do aluno cego na educação superior: percepções de professores de um curso de licenciatura em Química. ACTIO, Curitiba, v. 2, n. 1, p. 98-121, jan./jul. 2017.

BOGDAN, R. C.; BIKLEN, S. K. Investigação qualitativa em educação: uma introdução à teoria e aos métodos. 12. ed. Porto: Porto, 2003.

BRASIL. Lei Federal no 9394/96 que institui a Lei de Diretrizes e Bases da Educação Nacional. Brasília: Presidência da República/Casa Civil/Subchefia para Assuntos Jurídicos, 1996.

BRASIL. Lei Federal no 13.146 que institui a Lei Brasileira de Inclusão da Pessoa com Deficiência (Estatuto da Pessoa com Deficiência). Brasília: Presidência da República. Casa Civil. Subchefia para Assuntos Jurídicos, 2015. 
TOYAMA, K. S. F.; PRAIS, J. L. de S.; FIGUEIREDO, M. C.

BRASIL. Ministério da Educação. Secretaria de Educação Especial. Política Nacional de Educação Especial na Perspectiva da Educação Inclusiva. Brasília: Secretaria de Educação Especial, 2008.

CERQUEIRA, J. B.; FERREIRA, M. A. Os recursos didáticos na educação especial. Revista Benjamin Constant. Rio de Janeiro: 15. ed., abril de 2000.

COMUNIDADE APRENDER CRIANÇA. Cartilha da Inclusão Escolar: inclusão baseada em evidências científicas. São Paulo: Instituto Glia, 2014.

DINIZ, M. Inclusão de pessoas com deficiência e/ou necessidades específicas: avanços e desafios. Belo Horizonte: Autêntica Editora, 2012.

LÜDKE, M.; ANDRÉ, M. E. D. A. Pesquisa em educação: abordagens qualitativas. São Paulo: EPU, 1986.

MANTOAN, M. T. E. Inclusão escolar: o que é? Por quê? Como fazer? São Paulo: Summus, 2015.

MEYER, A.; ROSE, D.; GORDON, D. Universal Design for Learning (UDL). Estados Unidos: CAST, 2002.

MORAES, R.; GALIAZZI, M. C. Análise Textual Discursiva: processo constitutivo de múltiplas faces. Ciência \& Educação, São Paulo, v.12, n.1, p. 117-128, abr. 2006.

NUNES, S.; LOMÔNACO, J. F. B. O aluno cego: preconceitos e potencialidades. Scielo. Disponível em: https://www.scielo.br/scielo.php?script=sci_arttext\&pid=S1413$\underline{8572010000100006 \& l n g=p t \& t l n g=p t}$. Acesso em: 18 jun. 2020.

PAZ, G. L.; PACHECO, H. F.; COSTA NETO, C. O.; CARVALHO, R. C. P. S. Dificuldades no ensino-aprendizagem de Química no ensino médio em algumas escolas públicas da região sudeste de Teresina. In: $8^{\circ}$ Simpósio Brasileiro de Educação Química, 2010, Natal. Anais eletrônicos... Natal: SIMPEQUI, 2010. Disponível em: http://www.abq.org.br/simpequi/2010/trabalhos/196-4222.htm. Acesso em: 15 jul. 2020.

PIRES, R. F. M. Proposta de guia para apoiar a prática pedagógica de professores de Química em sala de aula inclusiva com alunos que apresentam deficiência visual. 2010.158 f. Dissertação de Mestrado (Programa de Pós-graduação em Ensino de Ciências) - Universidade de Brasília, Brasília, 2010.

PRAIS, J. L. S. Formação inclusiva com licenciandas em Pedagogia: ações pedagógicas baseadas no Desenho Universal para a Aprendizagem. 431 f. Dissertação (Mestrado) Programa de Pós-Graduação em Ensino de Ciências Humanas, Sociais e da Natureza (PPGEN), Universidade Tecnológica Federal do Paraná. Londrina, 2016.

Inter-Ação, Goiânia, v.46, n.1, p. 1-16, jan./mar. 2021. Disponível em: <http://dx.doi.org/10.5216/ia.v45i3.64893>. 
PRAIS, J. L. S. Das intenções à formação docente para a inclusão: contribuições do desenho universal para a aprendizagem. 1 ed. Curitiba: Appris, 2017.

SÁ, E. D.; CAMPOS, I. M.; SILVA, M. B. C. Atendimento Educacional Especializado: Deficiência Visual. SEESP/SEED/MEC. Brasília, 2007. Disponível em: http://portal.mec.gov.br/seesp/arquivos/pdf/aee_dv.pdf. Acesso em: 11 jun. 2020.

SAMPAIO, L. F.; MÓL, G. S. Educação inclusiva nas aulas de Química. vol. 12. Texto de apoio (Programa de pós-graduação em Ensino de Ciências) - Universidade de Brasília: Brasília, 2017.

TOYAMA, K. S. F. Orientações didáticas para o ensino de Química na perspectiva inclusiva: a elaboração e o uso de materiais adaptados para alunos cegos. 2019. $84 \mathrm{f}$. Trabalho de Conclusão de Curso (Curso de Licenciatura em Química). Universidade Tecnológica Federal do Paraná- UTFPR. Londrina, Paraná.

UNESCO. Declaração de Salamanca sobre princípios, política e práticas na área das necessidades educativas especiais, 1994 . Disponível em: https://unesdoc.unesco.org/ark:/48223/pf0000139394. Acesso em: 11 jun. 2020.

Karla Suzi Furutani Toyama: Mestranda no Programa de Pós-Graduação em Ensino de Ciências Humanas, Sociais e da Natureza (PPGEN) na Universidade Tecnológica Federal do Paraná (UTFPR), Campus Londrina. Licenciada em Química.

Orcid: https://orcid.org/0000-0001-6849-2564

E-mail: karla.ksft@smail.com

Jacqueline Lidiane de SouZA Prais: Doutora em Educação pela Universidade Estadual de Londrina (UEL). Mestra em Ensino, Especialista em Educação Especial Inclusiva e Políticas Públicas para Educação, Licenciada em Pedagogia. Docente na Educação Básica e na Educação Superior.

Orcid: https://orcid.org/0000-0002-3658-7021

E-mail: jacqueline_lidiane@hotmail.com

Marcia Camilo Figueiredo: Doutora em Educação para a Ciência (UNESP), campus

Bauru. Professora Adjunta na Universidade Tecnológica Federal do Paraná, Campus Londrina (UTFPR), Departamento Acadêmico de Química, Licenciatura em Química.

Orcid: https://orcid.org/0000-0001-5651-5984

E-mail: marciafigueired@utfpr.edu.br

Este periódico utiliza a licença Creative Commons Attribution 3.0, para periódicos de acesso aberto (Open Archives Iniciative - OAI). 